\title{
A Biomaterial Composed of Collagen and Solubilized Elastin Enhances Angiogenesis and Elastic Fiber Formation Without Calcification
}

\author{
WILLEKE F. DAAMEN, Ph.D., ${ }^{1}$ SUZAN T.M. NILLESEN, M.Sc., ${ }^{1}$ RONNIE G. WISMANS, M.Sc., 1 \\ DIETER P. REINHARDT, Ph.D., ${ }^{2}$ THEO HAFMANS, B.Sc., ${ }^{1,3}$ JACQUES H. VEERKAMP, Ph.D., ${ }^{1}$ \\ and TOIN H. VAN KUPPEVELT, Ph.D. ${ }^{1}$
}

\begin{abstract}
Elastin is the prime protein in elastic tissues that contributes to elasticity of, for example, lung, aorta, and skin. Upon injury, elastic fibers are not readily replaced, which hampers tissue regeneration. Incorporation of solubilized elastin (hydrolyzed insoluble elastin fibers or elastin peptides) in biomaterials may improve regeneration, because solubilized elastin is able to promote proliferation as well as elastin synthesis. Porous biomaterials composed of highly purified collagen without and without elastin fibers or solubilized elastin were prepared by freezing and lyophilization. Solubilized elastin formed spherical structures that were incorporated in the collagenous part of the scaffolds and that persisted after chemical crosslinking of the scaffolds. Crosslinked scaffolds were subcutaneously implanted in young Sprague Dawley rats. Collagensolubilized elastin and collagen scaffolds showed no calcification in this sensitive calcification model, in contrast to scaffolds containing elastin fibers. Collagen-solubilized elastin scaffolds also induced angiogenesis, as revealed by type IV collagen staining, and promoted elastic fiber synthesis, as shown with antibodies against rat elastin and fibrillin-1. It is concluded that scaffolds produced from collagen and solubilized elastin present a non-calcifying biomaterial with a capacity for soft-tissue regeneration, especially in relation to elastic fiber synthesis.
\end{abstract}

\section{INTRODUCTION}

$\mathbf{E}$ LASTIN IS THE MAJOR INSOLUBLE PROTEIN present in elastic tissue, contributing to the elasticity of lung, aorta, ligaments, and skin. Elastic fibers are not readily replaced upon injury, ${ }^{1}$ probably because of difficulties in recapitulating normal developmental expression patterns of tropoelastin and associated molecules. ${ }^{2,3}$ This seriously hampers tissue regeneration.

Solubilized elastin (obtained by hydrolyzing insoluble elastin) may markedly improve tissue regeneration, because it exhibits multiple biological effects. These include enhanced cell migration, ${ }^{4}$ cell proliferation, ${ }^{5}$ and elastin synthesis. ${ }^{6,7}$ Solubilized elastin interacts with the elastin-laminin receptor, which is composed of 3 subunits: 2 transmembrane subunits of 61 and $55 \mathrm{kDa}$ and 1 extracellular subunit of $67 \mathrm{kDa}$, the latter binding tropoelastin and other elastin-like molecules. The receptor is present on a large number of cells, including fibroblasts, vascular smooth muscle cells, endothelial cells, chondrocytes, monocytes, lymphocytes, and polymorphonuclear leukocytes, and its signal transduction pathway is mediated through a pertussis toxin-sensitive G-protein. ${ }^{8-11}$ In

\footnotetext{
${ }^{1}$ Department of Biochemistry 280, Nijmegen Centre for Molecular Life Sciences, Radboud University Nijmegen Medical Centre, Nijmegen, The Netherlands.

${ }^{2}$ Faculty of Medicine, Department of Anatomy and Cell Biology and Faculty of Dentistry, McGill University, Montreal, Canada.

${ }^{3}$ Department of Pulmonary Diseases 454, Radboud University Nijmegen Medical Centre, Nijmegen, The Netherlands.
} 
addition to the elastin-laminin receptor, other receptors may play a role as well (e.g., integrins). ${ }^{12}$ Biomaterials containing solubilized elastin may thus exert biological effects on a wide variety of cell types.

We have previously prepared biomaterials composed of highly purified type I collagen and elastin fibers and studied their tissue reaction. ${ }^{13,14}$ In young Sprague Dawley rats (but not in adult rats), implantation of these scaffolds resulted in calcification of elastin fibers. Although initiation of tissue calcification does not require a cellular response, ${ }^{15}$ the in vivo milieu can accelerate the process ${ }^{16}$ (e.g., through the extracellular release of enzymes by macrophages and giant cells involved in elastin degradation). ${ }^{17-20}$

We here hypothesize that porous scaffolds containing solubilized elastin may improve synthesis of elastin through interaction with the elastin-laminin receptor. ${ }^{6}$ Furthermore, if enzymes involved in elastin degradation play a role in increasing calcification, application of solubilized elastin may reduce the presence of macrophages and giant cells and thus reduce calcification. In addition, solubilized elastin is less hydrophobic and more charged than insoluble elastin. Negative charges from C-terminal carboxylic groups may prevent positively charged calcium ions from precipitating in the same way, because negatively charged sulfate groups have been shown to suppress calcium binding to, for example, polyurethane. ${ }^{21}$ In this study, we therefore prepared and characterized collagen, collagen-elastin fibers, and collagen-solubilized elastin scaffolds and studied calcification, angiogenesis, and elastin synthesis after subcutaneous implantation.

\section{MATERIALS \& METHODS}

\section{Materials}

Mouse anti-bovine elastin immunoglobulin (Ig)G clone BA-4 was purchased from Sigma Chemical Co. (St Louis, MO); goat anti-rat alpha-elastin from Elastin Products Co. (Owensville, MO); rabbit anti-bovine type I collagen, rabbit anti-rat type I collagen, and rabbit anti-rat type III collagen IgGs from Chemicon (Temecula, CA); and goat anti-human type IV collagen IgG from Southern Biotechnology Inc. (Birmingham, AL). Rabbit anti-human fibrillin-1 (pAb-rF6H) and rabbit anti-human fibrillin-2 (anti-rFBN2-1) anti-sera were prepared as described previously. ${ }^{22,23}$ Alexa488- and Alexa594-labeled secondary antibodies were from Molecular Probes Europe (Leiden, The Netherlands), and rabbit anti-goat peroxidase and 3,3-di-aminobenzidine tetrahydrochloride (DAB) were from DAKO (Glostrup, Denmark).

\section{Isolation of scaffolds components}

Insoluble type I collagen was purified from bovine Achilles tendon. Briefly, tendons were cleaned from noncollagenous tissue, pulverized under liquid nitrogen con- ditions using a Pulverisette 19 with a 0.5 -mm sieve (Fritsch, Idar-Oberstein, Germany), and consecutively rinsed extensively with $0.1 \mathrm{M}$ sodium chloride $(\mathrm{NaCl})$ in $50 \mathrm{mM}$ Tris-hydrochloric acid ( $\mathrm{HCl}) \mathrm{pH} 7.2,1.0 \mathrm{M} \mathrm{NaCl}$ in $50 \mathrm{mM}$ Tris- $\mathrm{HCl} \mathrm{pH} 7.2,4 \mathrm{M}$ urea in $0.5 \mathrm{M}$ acetic acid, $0.5 \mathrm{M}$ acetic acid, acetone, and demineralized water. ${ }^{24}$

Insoluble elastin fibers $\left(\mathrm{EL}_{\mathrm{fiber}}\right)$ were isolated from equine ligamentum nuchae. Non-elastinous tissue was removed, and ligaments were pulverized under liquid nitrogen conditions through a $1.0 \mathrm{~mm}$ sieve. The pulverized ligament was then washed and treated with $1 \mathrm{M} \mathrm{NaCl}$ in $10 \mathrm{mM}$ phosphate buffer $\mathrm{pH} 7.4$ (PB), various organic solvents, formic acid with cyanogen bromide, $4 \mathrm{M}$ urea plus $1 \mathrm{M}$ 2-mercaptoethanol in $0.1 \mathrm{M} \mathrm{PB}$, trypsi, and $1 \mathrm{M} \mathrm{NaCl}$ in $10 \mathrm{mM}$ PB. ${ }^{25}$ Solubilized elastin $\left(\mathrm{EL}_{\mathrm{sol}}\right)$ was prepared from insoluble elastin fibers using oxalic acid hydrolysis. ${ }^{26}$

Briefly, $10 \mathrm{~g}$ of elastin was hydrolyzed for $1 \mathrm{~h}$ with $75 \mathrm{~mL}$ $0.25 \mathrm{M}$ oxalic acid at $95^{\circ} \mathrm{C}$. Then the preparation was quickly cooled on ice and centrifuged, and the supernatant was collected. The pellet was hydrolyzed again for $1 \mathrm{~h}$ with oxalic acid, followed by cooling and centrifuging. This procedure was repeated until all insoluble material was solubilized (generally after a total of 14 steps). Supernatants were pooled, dialyzed against $10 \mathrm{mM} \mathrm{PB}$, and subsequently dialyzed against MilliQ water using Amicon Ultra-15 10 kDa MWCO filter tubes (Millipore, Billerica, MA).

\section{Characterization of solubilized elastin preparation}

The amount of solubilized elastin in the elastin pool was determined according to the method develop by Lowry, ${ }^{27}$ size of elastin using 1-dimensional gel electrophoresis (4\% polyacrylamide gel with silver staining), ${ }^{28}$ and gel permeation chromatography $^{29}$ [column material: Sephacryl S-500, reference samples: ferritin (0.88 MDa), dextran blue (2 MDa), and Helix pomatia hemocyanin (9MDa)], size-charge distribution using 2-dimensional gel electrophoresis, ${ }^{30}$ amine group content after reaction with 2,4,6-trinitrobenzene sulfonic acid, ${ }^{31}$ and amino acid composition using a Biochrom 20 amino acid analyser (Amersham Pharmacia Biotech, Uppsala, Sweden). ${ }^{32}$

\section{Preparation of scaffolds}

Various scaffolds were prepared composed of collagen only (COL); collagen plus insoluble elastin fibers in a 1:1 ratio $\left(\mathrm{COL}-\mathrm{EL}_{\text {fiber }}\right)$; and collagen with solubilized elastin in 97:3, 9:1, and 1:1 ratios (COL-EL sol $)$.

Briefly, a $2 \%(\mathrm{w} / \mathrm{v})$ protein suspension (collagen without or with elastin fibers) was shaken overnight in $0.5 \mathrm{M}$ acetic acid at $4{ }^{\circ} \mathrm{C}$. If appropriate, $\mathrm{EL}_{\text {sol }}$ was added and the suspension diluted to $1 \%(\mathrm{w} / \mathrm{v})$ with cold MilliQ water and homogenized on ice using a Potter-Elvehjem homogenizer. Air-bubbles were removed by centrifuging at $250 \mathrm{~g}$ for $10 \mathrm{~min}$ at $4{ }^{\circ} \mathrm{C}$. The suspension was then slowly poured into a plastic mould, frozen in a bath of ethanol and solid carbon 
dioxide $\left(\mathrm{CO}_{2}\right)\left(-80^{\circ} \mathrm{C}\right)$ and lyophilized in a Zirbus lyophilizer (Bad Grund, Germany). For scaffolds composed of collagen plus $\mathrm{EL}_{\mathrm{sol}}$ in a 1:1 ratio, a suspension with a final concentration of $1.6 \%$ was used as well.

Scaffolds were applied as such (non-crosslinked) or crosslinked. For crosslinking, $200 \mathrm{mg}$ of scaffold was incubated for $4 \mathrm{~h}$ at $22^{\circ} \mathrm{C}$ with $20 \mathrm{~mL} 33 \mathrm{mM}$ 1-ethyl-3(3-dimethyl aminopropyl)carbodiimide (EDC) and $6 \mathrm{mM} \mathrm{N}$ hydroxysuccinimide (NHS) in $50 \mathrm{mM} 2$-morpholinoethane sulfonic acid (pH 5.0) containing 40\% ethanol. EDC/NHS crosslinked scaffolds were then washed with $0.1 \mathrm{M}$ disodium hydrogen phosphate (twice for $1 \mathrm{~h}$ ), $1 \mathrm{M} \mathrm{NaCl}$ (twice for $2 \mathrm{~h}$ ), $2 \mathrm{M} \mathrm{NaCl}$ (once overnight, 5 times for $30 \mathrm{~min}$ ), and MilliQ water ( 6 times for $30 \mathrm{~min}$ ). The scaffolds were then frozen in ethanol/ $/ \mathrm{CO}_{2}$ again and lyophilized. ${ }^{14,33}$ For in vivo experiments, EDC/NHS-crosslinked COL and COL-EL fiber $_{\text {f }}$ $1: 1$ scaffolds from a $1.0 \%$ suspension were used along with COL-EL $_{\text {sol }} 1: 1$ scaffolds from a $1.6 \%$ suspension.

\section{Characterization of scaffolds}

The amine group content was measured to evaluate the degree of crosslinking. ${ }^{31}$ The amount of $\mathrm{El}_{\mathrm{sol}}$ bound to collagen was established by estimating the protein content in the solution after crosslinking. Proteins in this solution were precipitated with $10 \%$ 2,4,6-trichloreacetic acid on ice for $2 \mathrm{~h}$ and centrifuged. The pellet was then dissolved in $10 \mathrm{mM}$ sodium hydroxide and the protein amount assayed according to the method developed by Lowry. ${ }^{27}$ The same procedure was applied to evaluate the in vitro release of $\mathrm{EL}_{\mathrm{sol}}$ from the scaffolds. Neither non-crosslinked nor EDC/NHScrosslinked collagen scaffolds gave any release of protein from the scaffolds after $24 \mathrm{~h}$ or 7 days in PBS, and therefore the protein release from COL-EL $\mathrm{E}_{\text {sol }}$ scaffolds could be attributed to $\mathrm{EL}_{\mathrm{sol}}$ only. Water-binding capacity of scaffolds was determined as previously described. ${ }^{14}$ Scanning electron microscopy was used to analyze the morphology of the scaffolds, ${ }^{14}$ transmission electron microscopy to determine the ultrastructure of the scaffolds, ${ }^{25}$ and immunofluorescence microscopy to study the distribution of $\mathrm{EL}_{\mathrm{sol}}$ in the scaffolds using mouse anti-bovine elastin (1:1000) as a primary antibody. ${ }^{13}$

\section{In vivo evaluation of scaffolds}

The Ethics Committee of the Radboud University Nijmegen Medical Centre approved the study. Sprague-Dawley rats (male, 3 weeks old) were purchased from Harlan (Zeist, The Netherlands) and housed 2 per cage. The animals were fed pelleted diet and water ad libitum. Scaffolds were washed in 70\% (v/v) ethanol and sterile PBS. Rats were anesthetized with isoflurane, and subcutaneous pockets were made to the right and left of 2 midline incisions on the back.

Punches $(\varnothing 6 \mathrm{~mm})$ of the scaffolds were implanted in the pockets at a distance of approximately $1 \mathrm{~cm}$ from the incisions (4 implants/rat). In this study, $6 \mathrm{COL}, 6 \mathrm{COL}-\mathrm{EL}_{\text {fiber, }}$,

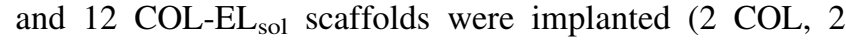

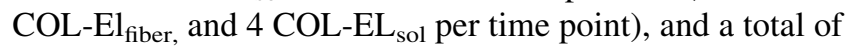
6 rats was used. Lower numbers of COL and COL-EL fiber scaffolds were used because these were compared with previous results. ${ }^{13}$ All scaffolds were crosslinked using EDC/ NHS. Implants with surrounding tissue were harvested at 3, 7, and 21 days after implantation. Immediately after explantation, scaffolds were divided in half. One half was processed for conventional histology and the other half for immunohistochemistry.

For conventional histology, explants were fixed in $4 \%$ (v/v) formaldehyde in PB for at least $24 \mathrm{~h}$ at $4^{\circ} \mathrm{C}$ and embedded in paraffin. Five- $\mu$ m sections were stained with hematoxylin-eosin, Elastin Van Gieson (visualization of elastin and collagen), or Von Kossa (visualization of calcium deposits). ${ }^{34}$ The total area of calcification in the scaffold was determined using Neurolucida software (MBF Bioscience, Williston, VT) and expressed as a percentage of the total implant size. Values were compared using the Student t-test, and $p<0.05$ was considered to be statistically significant. At least two persons performed histological evaluation independently.

Immunohistochemistry (immunofluorescence and DAB staining) was used to study the biodegradation of scaffold components and the formation of extracellular matrix by the host. Scaffolds were frozen in liquid nitrogen, and $5-\mu \mathrm{m}$ cryosections were mounted on superfrost slides and airdried. Immunofluorescence assay was performed as previously described. ${ }^{13}$ Primary antibodies used were mouse anti-bovine elastin (1:1000), rabbit anti-bovine type I collagen, goat anti-rat elastin, rabbit anti-rat type I collagen, rabbit anti-rat type III collagen (all 1:100), rabbit anti-human fibrillin-1, and rabbit anti-human fibrillin-2 (both 1:500). Antibodies were visualized with Alexa488- or Alexa594conjugated secondary antibodies diluted in PBS containing $5 \%$ normal rat serum. The antibody to bovine elastin also reacted with equine elastin, the antibodies against human fibrillin also reacted with rat fibrillin, and the antibody to bovine type I collagen did not substantially cross-react with rat type I collagen or vice versa. For immunohistochemistry with the DAB-staining method, cryosections were fixed with 4\% paraformaldehyde in PBS for $20 \mathrm{~min}$. Endogenous peroxidase was inhibited with $0.3 \%$ hydrogen peroxide $\left(\mathrm{H}_{2} \mathrm{O}_{2}\right)$ for $10 \mathrm{~min}$. After blocking for $30 \mathrm{~min}$ with $2 \%$ bovine serum albumin in PBS containing 0.1\% Tween (PBST), sections were incubated with goat anti-human type IV collagen (1:50) for $1 \mathrm{~h}$, washed, incubated for $1 \mathrm{~h}$ with rabbit anti-goat IgG peroxidase $(1: 100)$, and washed. Antibodies were diluted in PBST containing 5\% normal rabbit serum; washings were with PBST. Sections were washed with $50 \mathrm{mM}$ Tris- $\mathrm{HCl}(\mathrm{pH} 7.6)$ and incubated for $10 \mathrm{~min}$ with $\mathrm{DAB}$ $(0.5 \mathrm{mg} / \mathrm{mL})$ and ammonium nickel sulfate $(7.5 \mathrm{mg} / \mathrm{mL})$ in Tris-HCl. Finally, the reaction substrate was added $(0.2 \mu \mathrm{l}$ $30 \% \mathrm{H}_{2} \mathrm{O}_{2} / \mathrm{mL}$ ). Sections were washed, counterstained with hematoxylin, dehydrated, and embedded. The antibody to human type IV collagen cross-reacted with rat type IV 
collagen. The total area of blood vessels (including the lumen) in the scaffold was determined and expressed as a percentage of the total implant size using Neurolucida software. Values were compared using the Student t-test, and $p<0.05$ was considered to be statistically significant.

\section{RESULTS}

\section{Analysis of solubilized elastin preparation}

The solubilized elastin preparation was analyzed using sodium dodecyl sulfate polyacrylamide gel electrophoresis, which revealed that the molecular mass of the solubilized elastin ranged from 70 to over $880 \mathrm{kDa}$. Gel permeation chromatography gave a mean molecular mass of the solubilized elastin of approximately $1100 \mathrm{kDa}$. Two-dimensional gel electrophoresis showed that the elastin peptides had an isoelectric point of approximately 6 . The mean amine group content \pm standard deviation of the solubilized elastin was $292 \pm 5 \mathrm{nmol}$ amine groups per mg of protein. Amino acid composition of solubilized elastin was similar to that of elastin fibers for all amino acid residues, including desmosine and isodesmosine (both $0.5 \pm 0.0$ per 1000 amino acid residues).

\section{Analysis of scaffolds containing solubilized elastin}

Porous scaffolds were prepared using various ratios of collagen with $\mathrm{EL}_{\mathrm{sol}}$. After $4 \mathrm{~h}$ of crosslinking, less than $5 \%$ of $\mathrm{EL}_{\mathrm{sol}}$ could be retrieved from the remaining crosslinking solution. Hence, the crosslinking efficiency of $\mathrm{EL}_{\mathrm{sol}}$ to the scaffolds was at least $95 \%$. The biochemical characteristics of the scaffolds are summarized in Table 1. EDC/NHS crosslinking coupled $\mathrm{EL}_{\text {sol }}$ firmly to the scaffolds, because the in vitro release was only $2 \%$ after 7 days in the case of EDC/NHS-crosslinked collagen plus $\mathrm{EL}_{\mathrm{sol}}$ scaffolds, whereas it was $60 \%$ after only $24 \mathrm{~h}$ when crosslinking was omitted.

Collagen and $\mathrm{EL}_{\text {sol }}$ each possessed approximately $300 \mathrm{nmol}$ amine groups per $\mathrm{mg}$. Therefore, scaffolds made from these components had the same amount of amine groups for all ratios before crosslinking. After EDC/NHS crosslinking, approximately $60 \%$ of the amine groups remained for all scaffolds, indicating that $40 \%$ of the amine groups was used in the crosslinking reaction.

$\mathrm{EL}_{\mathrm{sol}}$ did not contribute to the water-binding activity of scaffolds. At a higher percentage of $\mathrm{EL}_{\mathrm{sol}}$, the water-

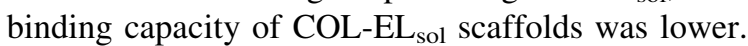

Using scanning electron microscopy (Fig. 1), non-

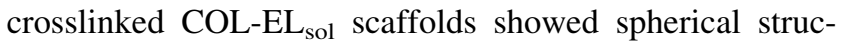
tures attached to collagenous fibrils or sheets. Spheres of different sizes (ranging from $\sim 200 \mathrm{~nm}$ to $10 \mu \mathrm{m}$ ) were found throughout the scaffolds. After crosslinking, these spheres deformed to some extent. COL and COL-EL $L_{\text {fiber }}$ scaffolds did not show this spherical organization. Immunofluorescence staining using an antibody against bovine elastin demonstrated that the spheres in COL-EL $\mathrm{sol}_{\text {scaffolds were }}$ composed of $\mathrm{EL}_{\mathrm{sol}}$ (Fig. 2A). The same was found based on the autofluorescence of elastin (Fig. 2B). Transmission electron microscopy showed that $\mathrm{EL}_{\mathrm{sol}}$ spheres in EDC/

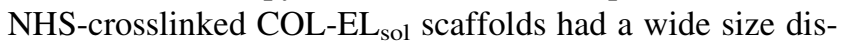
tribution and were mostly incorporated into the collagen

Table 1. Biochemical Characteristics of Scaffolds Prepared from Collagen, Collagen + Elastin Fibres and Collagen + Solubilised Elastin

\begin{tabular}{|c|c|c|c|c|c|}
\hline Scaffold & $\begin{array}{c}\text { Crosslinked } \\
\text { with EDC/NHS }\end{array}$ & $\begin{array}{c}\text { Release } \\
\text { after } 24 \mathrm{~h} \text { in } \mathrm{PBS} \\
{\left[\% \text { of total } E L_{\text {sol }}\right]}\end{array}$ & $\begin{array}{c}\text { Release after } \\
7 \text { days in } P B S \\
{\left[\% \text { of total } E L_{\text {sol }}\right]}\end{array}$ & $\begin{array}{c}\text { Amine group } \\
\text { content } \\
\text { [nmol/mg scaffold] }\end{array}$ & $\begin{array}{c}\text { Water-binding } \\
\text { capacity } \\
\text { [\# times dry weight] }\end{array}$ \\
\hline $\mathrm{EL}_{\mathrm{sol}} *$ & & & & $292 \pm 5$ & \\
\hline $\mathrm{COL}$ & - & $0 \pm 0.0$ & ND & $297 \pm 14$ & $20 \pm 1$ \\
\hline COL-EL ${ }_{\text {fiber }} 1: 1$ & - & ND & ND & $160 \pm 9$ & $16 \pm 2$ \\
\hline COL-EL ${ }_{\text {sol }} 97: 3$ & - & $58.0 \pm 11.8$ & ND & $300 \pm 3$ & $19 \pm 2$ \\
\hline $\mathrm{COL}-\mathrm{EL}_{\mathrm{sol}} 9: 1$ & - & $59.3 \pm 9.4$ & ND & $290 \pm 13$ & $19 \pm 1$ \\
\hline $\mathrm{COL} \mathrm{EL}_{\text {sol }} 1: 1$ & - & $62.3 \pm 53.3$ & ND & $298 \pm 18$ & $13 \pm 1$ \\
\hline $\mathrm{COL} \mathrm{EL}_{\mathrm{sol}} 1: 1(1.6)^{* *}$ & - & $66.2 \pm 7.2$ & ND & $290 \pm 10$ & $12 \pm 1$ \\
\hline $\mathrm{COL}$ & + & ND & $0 \pm 0.0$ & $189 \pm 5$ & $20 \pm 2$ \\
\hline COL-EL $L_{\text {fiber }} 1: 1$ & + & ND & ND & $98 \pm 6$ & $16 \pm 1$ \\
\hline COL-EL $_{\text {sol }} 97: 3$ & + & ND & $2.4 \pm 1.5$ & $190 \pm 15$ & $19 \pm 2$ \\
\hline $\mathrm{COL}_{-} \mathrm{EL}_{\mathrm{sol}}$ 9:1 & + & ND & $1.0 \pm 0.8$ & $171 \pm 4$ & $18 \pm 2$ \\
\hline COL-EL $_{\text {sol }} 1: 1$ & + & ND & $0.8 \pm 0.7$ & $163 \pm 5$ & $14 \pm 1$ \\
\hline $\mathrm{COL}-E L_{\mathrm{sol}} 1: 1(1.6)^{* *}$ & + & ND & $0.5 \pm 0.3$ & $154 \pm 12$ & $12 \pm 1$ \\
\hline
\end{tabular}

$\mathrm{COL}=$ collagen $; \mathrm{EL}_{\text {fiber }}=$ insoluble elastin fibers; $\mathrm{EL}_{\mathrm{sol}}=$ solubilised elastin; $\mathrm{ND}=$ not determined.

Results are mean $\pm \mathrm{SD}$ of 3 individual experiments.

*No scaffolds could be prepared of $\mathrm{EL}_{\mathrm{sol}}$ alone.

**COL-EL $\mathrm{sol}_{\mathrm{s}}$ 1:1 (1.6) scaffold was prepared from a 1.6\% suspension of collagen and $\mathrm{EL}_{\mathrm{sol}}$, whereas all other scaffolds were prepared from a $1.0 \%$ protein suspension. 


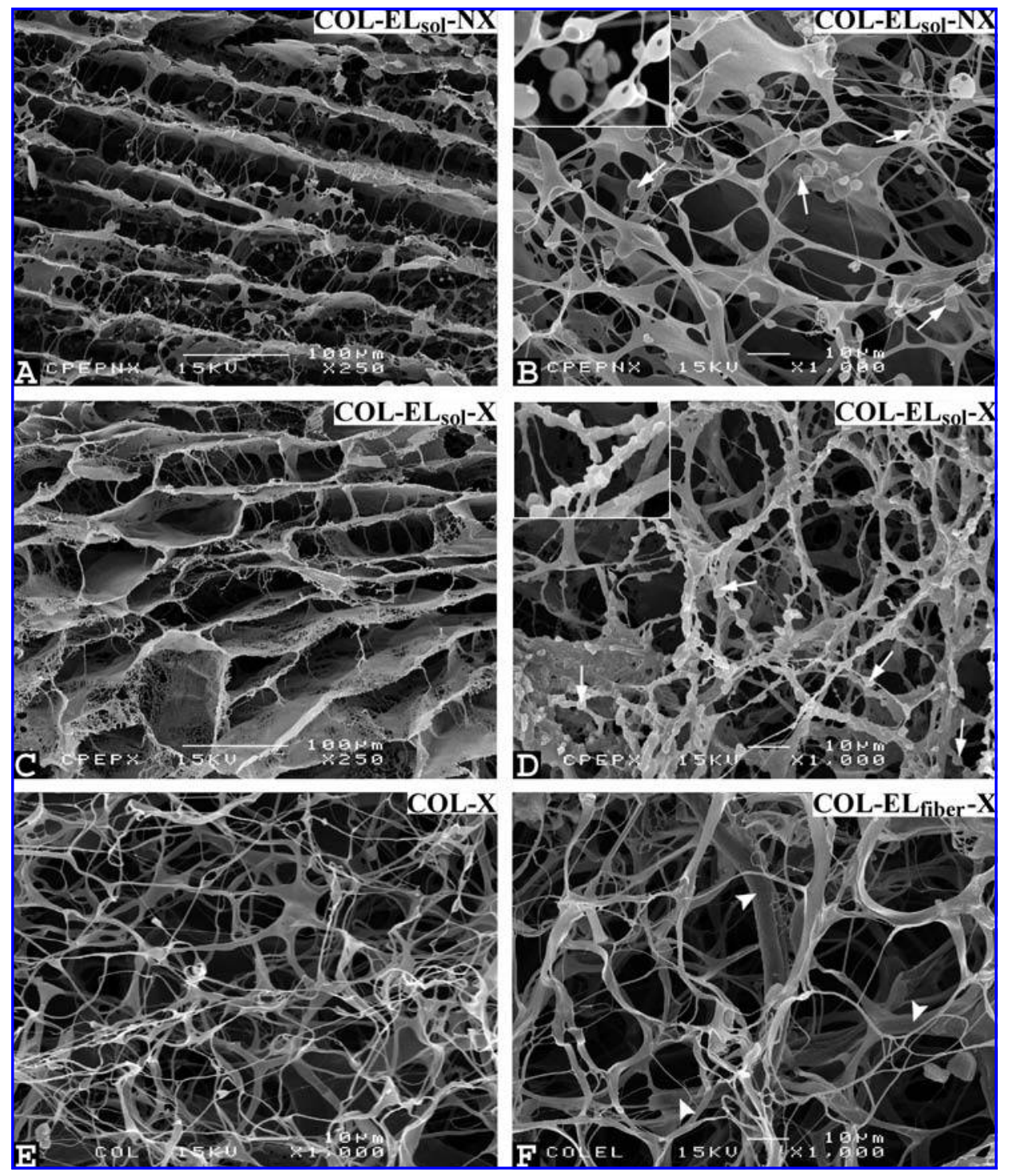

FIG. 1. Morphology of scaffolds as analyzed using scanning electron microscopy. (A, B) Non- crosslinked (NX) collagen with solubilized elastin (COL-EL sol $_{1}$ ); (C, D) 1-ethyl-3-(3-dimethyl aminopropyl)carbodiimide/6 mM N-hydroxysuccinimide (EDC/NHS)crosslinked (X) COL-EL sol $_{\text {, }}(\mathbf{E})$ collagen only $(\mathrm{COL})$ and $(\mathbf{F})$ collagen plus insoluble elastin fiber $\left(\mathrm{COL}-\mathrm{EL}_{\text {fiber }}\right) \mathbf{s c a f f o l d s}_{\mathrm{A}} \mathbf{A}$ and $\mathbf{C}$ represent cross-sectional views; $\mathbf{B}, \mathbf{D}, \mathbf{E}$, and $\mathbf{F}$ are enlarged top views. Arrowheads indicate insoluble elastin fibers in $\mathrm{COL}_{\mathrm{EL}} \mathrm{EL}_{\text {fiber }}$; arrows indicate spherical structures that are only present in the COL-EL sol. $_{\text {. Spherical structures in EDC/NHS-crosslinked COL-EL }}$ sol are

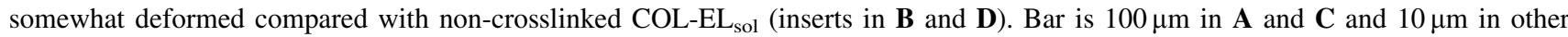
images.

network (Fig. 2C, D). The latter figure also shows a sphere with a less-dense outer core. Crosslinking does not occur instantaneously, which may cause this effect.

\section{Tissue response to implanted scaffolds}

All animals remained in good condition, and no infections were observed. Macroscopically, a thin capsule was seen around the scaffolds at explantation. In Table 2, an overview of calcification behavior and cellular response is given for the 3 different scaffolds. Tissue response to COL and COL-EL ${ }_{\text {fiber }}$ scaffolds was consistent with previous results. ${ }^{13}$

\section{Calcification of scaffolds}

In young Sprague-Dawley rats, COL-EL ${ }_{\text {sol }}$ and COL did not calcify at all in the time span investigated, in contrast to COL-EL fiber (Fig. 3). In COL-EL fiber $_{\text {especially, elastin fibers }}$ calcified from day 7 on. At day $7,3.5 \% \pm 0.1 \%$ of the total scaffold surface had calcified, whereas at day 21, it was $11.5 \% \pm 0.7 \%$, which was statistically significant $(p<0.05)$. 


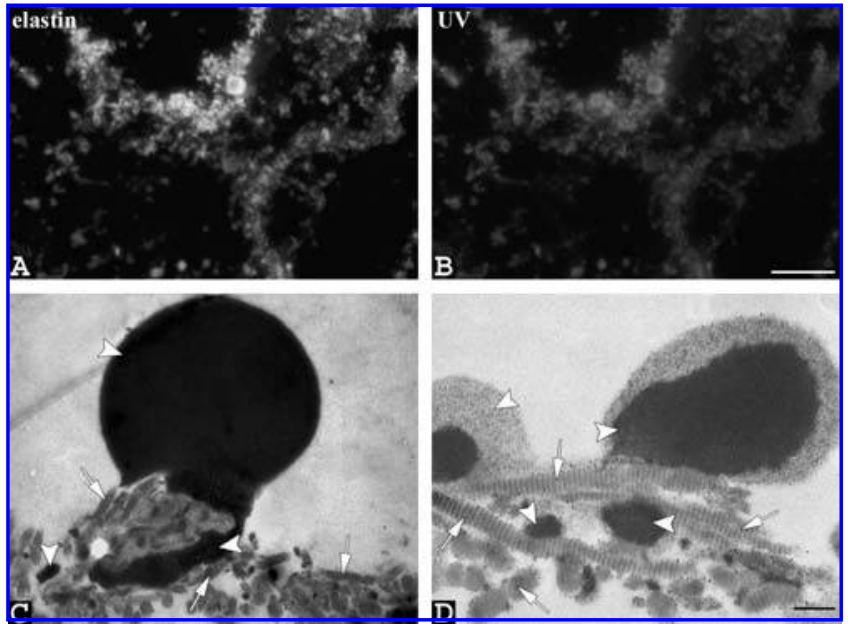

FIG. 2. Microscopical evaluation of spherical structures in collagen with solubilized elastin $\left(\mathrm{COL}-\mathrm{EL}_{\mathrm{sol}}\right)$ scaffolds. (A) Immunofluorescence staining for elastin and (B) autofluorescence visualization using ultraviolet optics in 1-ethyl-3-(3-dimethyl aminopropyl)carbodiimide/6 $\mathrm{mM}$ N-hydroxysuccinimide (EDC/ NHS)-crosslinked scaffolds show that spherical structures are composed of $\mathrm{EL}_{\mathrm{sol}}$. (C, D) Transmission electron microscopy images display that $\mathrm{EL}_{\text {sol }}$ spheres (white arrowheads) are incorporated in the collagenous structures (white arrows) of EDC/NHScrosslinked scaffolds. Bar is $50 \mu \mathrm{m}$ in $\mathbf{A}, \mathbf{B}$ and $0.25 \mu \mathrm{m}$ in $\mathbf{C}, \mathbf{D}$.

\section{Cellular response to scaffolds}

At day 3, cellular response to COL-EL $\mathrm{sol}_{\mathrm{sol}}$ showed moderate infiltration of neutrophilic granulocytes throughout the scaffold, whereas at day 7, fibroblasts and other mononuclear cells and few giant cells were found. At day 21, a greater number of phagocytic cells was observed, with strong proliferation of fibroblasts. Cellular reactions to COL and COL-EL $\mathrm{E}_{\text {fiber }}$ were considerably less. COL gave the mildest reaction; after 21 days, some macrophages and giant cells were present, mainly at the periphery of the scaffolds. At day 3, cellular response to COL-EL fiber $_{\text {included some }}$ neutrophilic granulocytes that had entered the outer part of the scaffold. At day 7, fibroblasts and other mononuclear cells were found in the scaffold, with some giant cells at the periphery of the scaffold, and at day 21, phagocytic cells like macrophages and giant cells dominated the scaffold, whereas the number of non-phagocytic cells had increased at the periphery. Although more macrophages were found in COL-EL ${ }_{\text {sol }}$, the number of giant cells in COL-EL $L_{\text {sol }}$ and COL-EL fiber $_{\text {was similar. }}$

\section{Vascularization of scaffolds}

Type IV collagen (present in endothelial basement membranes) was used as a marker for blood vessels (Fig. 4). At day 3, no blood vessels were observed in the scaffolds, although they were found in the surrounding tissue. At day 7, COL-EL sol $_{\text {showed more blood vessels than COL-El }}$ fiber and COL, but differences were not statistically significant. At day 21, blood vessels were also most abundant in COL$\mathrm{EL}_{\mathrm{sol}}$, both at the periphery and within the scaffold, accompanied by more large blood vessels. COL-EL sol $_{\text {now }}$ contained a significantly larger area of blood vessels than COL-El $l_{\text {fiber }}$ and COL. At this time, COL-EL fiber $_{\text {also had }}$ statistically significantly more blood vessels than COL. In this scaffold, vascularization was also present at the periphery, but considerably fewer vessels were found within the scaffold. In COL, blood vessels were found mainly at the periphery of the scaffolds.

Table 2. General Overview of Calcification and Cellular Events after Subcutaneous Implantation of the Scaffolds in Young Sprague Dawley Rats

\begin{tabular}{|c|c|c|c|c|c|c|}
\hline Scaffold & $\begin{array}{l}\text { Implantation } \\
\text { time (days) }\end{array}$ & Calcification & $P M N s$ & $\begin{array}{l}\text { Phagocytic } \\
\text { cells }\end{array}$ & $\begin{array}{c}\text { Non-phagocytic } \\
\text { cells* }\end{array}$ & $\begin{array}{c}\text { Blood } \\
\text { vessels } * *\end{array}$ \\
\hline \multirow[t]{3}{*}{ COL } & 3 & - & $\mathrm{sp}$ & $\mathrm{sp}$ & - & - \\
\hline & 7 & - & - & \pm & $\mathrm{sp}$ & $\mathrm{sp}$ \\
\hline & 21 & - & - & + & \pm & \pm \\
\hline \multirow[t]{3}{*}{ COL-EL ${ }_{\text {fiber }}$} & 3 & - & \pm & \pm & $\mathrm{sp}$ & - \\
\hline & 7 & \pm & $\mathrm{sp}$ & + & \pm & \pm \\
\hline & 21 & + & - & + \pm & + & + \\
\hline \multirow[t]{3}{*}{ COL-EL ${ }_{\text {sol }}$} & 3 & - & + \pm & \pm & $\mathrm{sp}$ & - \\
\hline & 7 & - & $\mathrm{sp}$ & + & \pm & + \\
\hline & 21 & - & - & ++ & ++ & ++ \\
\hline
\end{tabular}

*Absolute numbers of non-phagocytic cells were lower than of phagocytic cells, e.g. ++ for phagocytic and giant cells refers to more cells than ++ for non-phagocytic cells.

**B Blood vessels were assessed by immunostaining for rat type IV collagen, present in vascular basement membranes. PMNs = polmorphic nuclear cells, i.e. granulocytes; phagocytic cells include macrophages, giant cells and monocytes; non-phagocytic cells include fibroblasts, lymphocytes and plasma cells. Events were scored ranging from sporadic (sp) to abundant $(++)$. -: not present. 


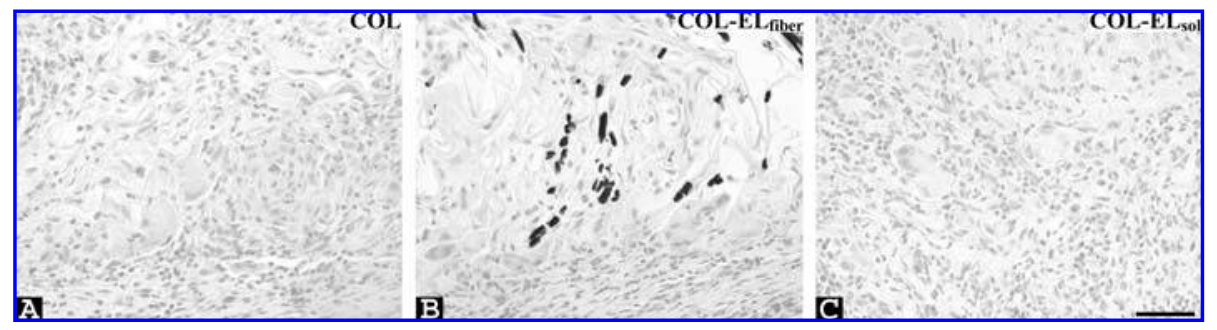

FIG. 3. Light microscopy evaluation of calcification of scaffolds 21 days after implantation in young Sprague-Dawley rats. (A) Collagen alone $(\mathrm{COL}),(\mathbf{B})$ collagen plus insoluble elastin fiber $\left(\mathrm{COL}-\mathrm{El}_{\text {fiber }}\right)$, (C) collagen with solubilized elastin $\left(\mathrm{COL}-\mathrm{EL}_{\text {sol }}\right)$ scaffold. Calcium deposits have an intense black color due to Von Kossa staining and are only found in COL-EL $L_{\text {fiber }}$ Bar is $50 \mu \mathrm{m}$.
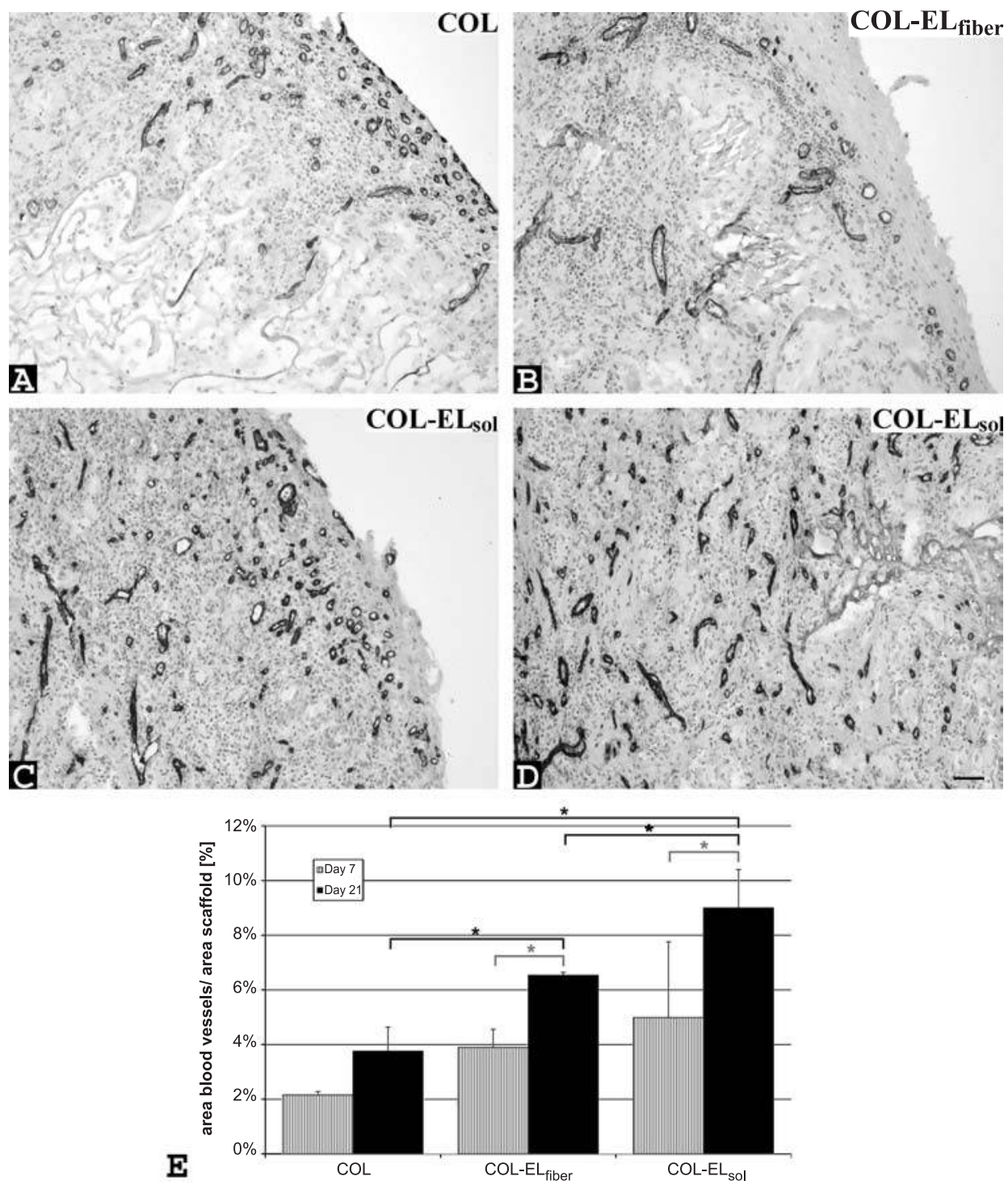

FIG. 4. Light microscopical evaluation of angiogenesis in scaffolds 21 days after implantation in young Sprague-Dawley rats. Sections were stained for type IV collagen as a marker for blood vessels. (A) Collagen alone (COL), (B) collagen plus insoluble elastin fiber $\left(\mathrm{COL}-\mathrm{El}_{\text {fiber }}\right)$, (C) periphery of collagen with solubilized elastin $\left(\mathrm{COL}-\mathrm{EL}_{\mathrm{sol}}\right)$, (D) within COL-EL $\mathrm{sol}_{\mathrm{Scaffold}} \mathrm{Bar}$ is $50 \mu \mathrm{m}$. (E) Quantification of the blood vessels in the scaffold using type IV collagen and expressed as a percentage of the total scaffold area. At day $21, \mathrm{COL}-\mathrm{EL}_{\mathrm{sol}}$ had significantly more blood vessels than COL and COL-EL $\mathrm{fiber}^{*} p<0.05$. 
Table 3. Overview of Immunostaining Results of Explants for Scaffold and Rat Extracellular Matrix Components

\begin{tabular}{|c|c|c|c|c|c|c|}
\hline Scaffold & $\begin{array}{c}\text { Days after } \\
\text { implantation }\end{array}$ & $\begin{array}{c}\text { Scaffold } \\
\text { elastin }\end{array}$ & $\begin{array}{l}\text { Scaffold } \\
\text { collagen }\end{array}$ & $\begin{array}{l}\text { Rat } \\
\text { elastin }\end{array}$ & $\begin{array}{c}\text { Rat } \\
\text { type I collagen }\end{array}$ & $\begin{array}{c}\text { Rate type III } \\
\text { collagen }\end{array}$ \\
\hline \multirow[t]{3}{*}{$\mathrm{COL}$} & 3 & - & ++ & - & $\mathrm{sp}$ & - \\
\hline & 7 & - & ++ & $\mathrm{sp}$ & \pm & \pm \\
\hline & 21 & - & + \pm & $\mathrm{sp}$ & \pm & + \\
\hline \multirow[t]{3}{*}{ COL-EL $L_{\text {fiber }}$} & 3 & ++ & ++ & - & $\mathrm{sp}$ & - \\
\hline & 7 & ++ & ++ & $\mathrm{sp}$ & \pm & + \\
\hline & 21 & + & + & \pm & + & ++ \\
\hline \multirow[t]{3}{*}{ COL-EL ${ }_{\text {sol }}$} & 3 & ++ & ++ & - & $\mathrm{sp}$ & $\mathrm{sp}$ \\
\hline & 7 & ++ & + \pm & \pm & \pm & + \\
\hline & 21 & + & + & + & + \pm & ++ \\
\hline
\end{tabular}

Events were scored ranging from sporadic (sp) to abundant $(++)$. -: not present.

\section{Scaffold degradation and new matrix synthesis}

Table 3 gives an overview of the immunostaining for scaffold components and newly formed extracellular matrix molecules at different times.

\section{Scaffold degradation}

Scaffold degradation was studied using conventional histology and immunohistochemistry with antibodies for scaffold elastin and collagen. From day 7, elastin staining

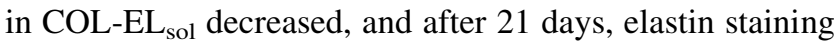
was reduced even more. Elastin spheres were still present at this time, especially in the central part of the scaffolds (Fig. 5A, B). At the periphery of the scaffolds, staining intensity was less, and spheres were smaller, suggesting resorption and degradation. Collagen gradually decreased with time. Elastin fiber fragments (smaller than the implanted elastin fibers) were found from day 7 on in COL-EL $L_{\text {fiber }}$. At day 21 , less elastin staining and more elastin fragments were observed in these scaffolds. In the same scaffold, thinner and fragmented collagen structures were visible mainly at the periphery of the scaffolds from day 7 on.

At day 21, degraded collagen was also found more centrally, whereas only minor amounts of fragmented col- lagen were found in COL. Elastin and collagen degradation

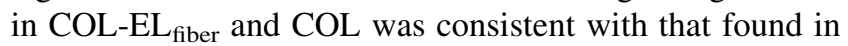
previous studies. ${ }^{13}$

\section{Collagen formation}

Generally, most staining for rat type I and type III collagen was found in COL-EL $\mathrm{Es}_{\mathrm{so}}$, somewhat less in COL$\mathrm{EL}_{\text {fiber }}$, and least in COL. In all scaffolds, staining for type I and III collagen started in the fibrous capsule and at the periphery of the scaffolds from day 7 on (results not shown). In general, new rat collagen fibers aligned with original

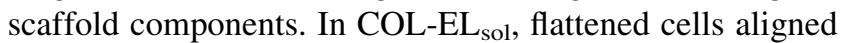
with the lamellar scaffold structures, and this was accompanied by extracellular matrix formation (Fig. 5C). Type IV collagen staining was present in blood vessels as shown under vascularization of scaffolds (Fig. 4).

\section{Elastic fiber formation}

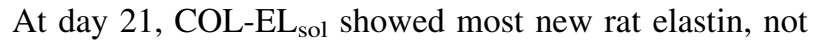
only in blood vessels, but also as thread-like structures within the scaffold (Fig. 6). In COL-EL ${ }_{\text {fiber, }}$, rat elastin was found mainly in blood vessels present in the capsule around

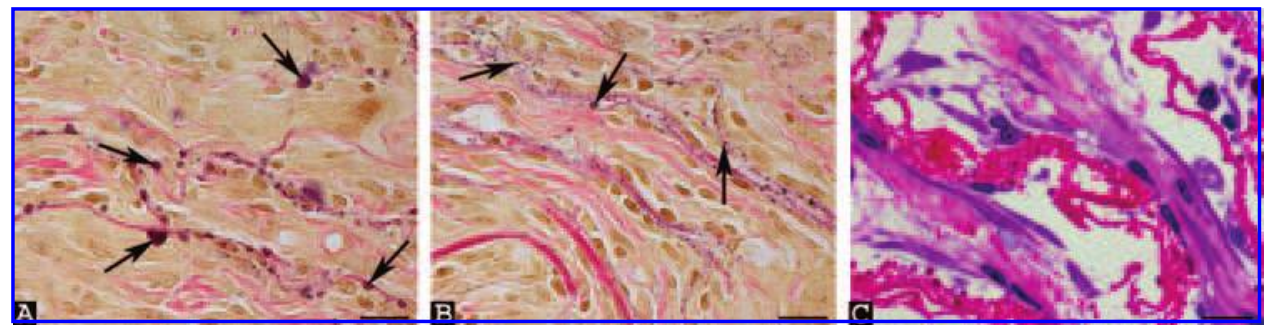

FIG. 5. (A-B) Elastin Van Gieson-stained paraffin sections of collagen with solubilized elastin $($ COL-EL sol $)$ scaffolds shows that $\mathrm{EL}_{\mathrm{sol}}$ spheres from the scaffold are still present 21 days after implantation in young Sprague-Dawley rats. Within the scaffolds, elastin spheres (arrows) are still quite large (A), but at the periphery of the scaffolds, the elastin spheres are smaller (B). Elastin Van Gieson stains elastin black and collagen pink or red. Bars represent $20 \mu \mathrm{m}$. (C) Semi-thin epon sections of crosslinked COL-EL sol $_{\text {scaffolds that }}$ were implanted for 7 days in young Sprague-Dawley rats stained with toluidine blue and basic fuchsin. Flattened cells aligned with the scaffold lamellar structures and were accompanied by extracellular matrix formation. Cells stain blue, new extracellular matrix stains light pink, and scaffold material stains dark pink. Bars represent $10 \mu \mathrm{m}$. Color images available online at www.liebertpub.com/ten. 


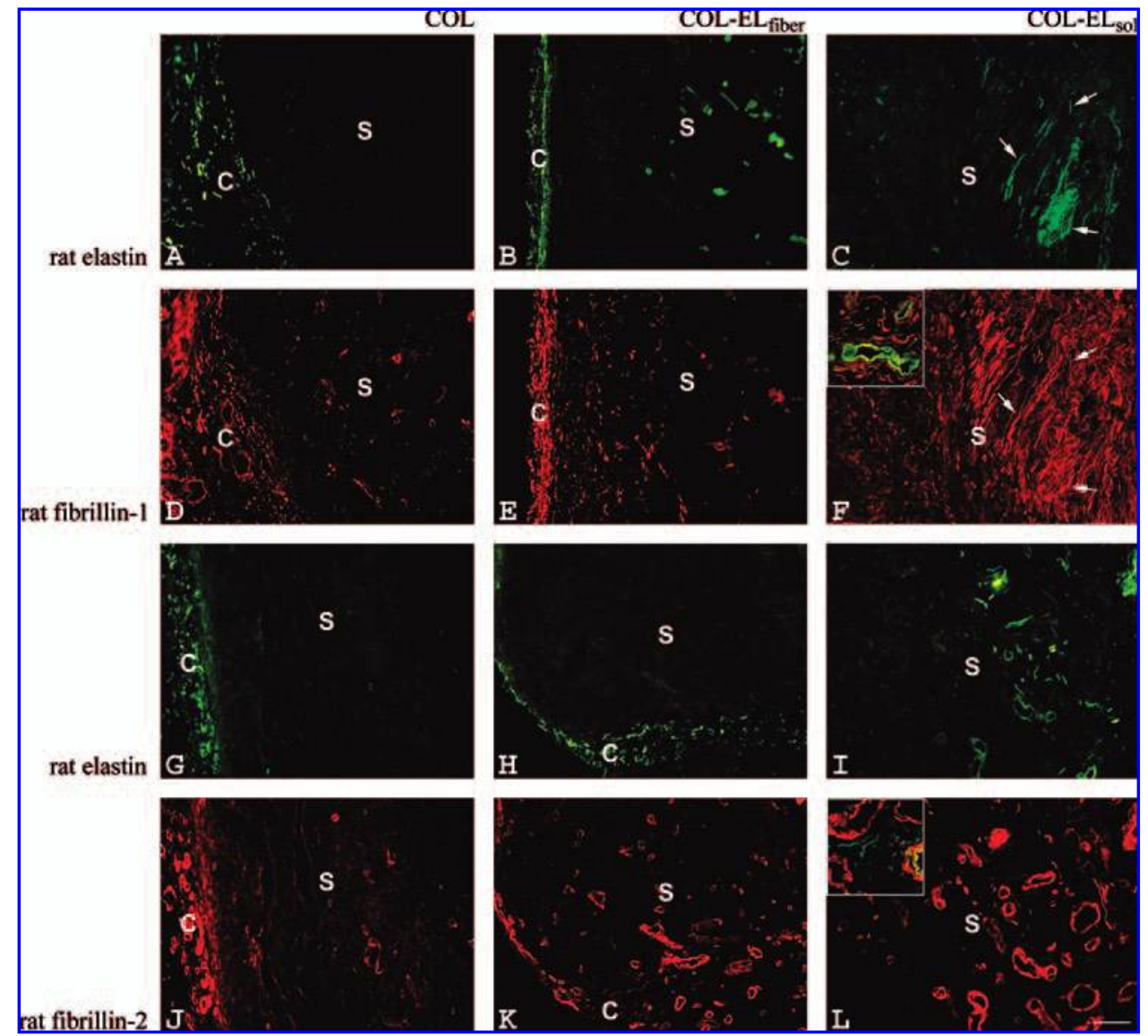

FIG. 6. Fluorescence microscopy evaluation of newly formed elastic fibers in scaffolds, 21 days after implantation in young SpragueDawley rats. Sections were stained for rat elastin (A-C, G-I), fibrillin-1 (D-F), and fibrillin-2 (J-L). Especially in collagen with solubilized elastin $\left(\mathrm{COL}-\mathrm{EL}_{\mathrm{sol}}\right)$ scaffolds, thread-like structures (arrows) positive for rat elastin and fibrillin-1 were observed. Blood vessels mainly colocalized with fibrillin-2 and to a lesser extent with fibrillin-1 staining. Insert in $\mathbf{F}$ shows an example of colocalized rat elastin and fibrillin-1 in blood vessels; insert in $\mathbf{L}$ shows that thin rat elastin fibers do not colocalize with fibrillin-2. C, capsule; S, scaffold. Bar is $50 \mu \mathrm{m}$. Color images available online at www.liebertpub.com/ten.

the implant, and small amounts of thin elastic fibers were found sporadically at the periphery of the scaffolds. In $\mathrm{COL}$, rat elastin was present only in blood vessels in the capsule.

In blood vessels, rat elastin colocalized with fibrillin-1 and fibrillin-2 staining. Fibrillin-2 staining was mainly present in blood vessels (Fig. 6J-L), but not all blood vessels contained newly formed elastin (Fig. 6G-I). Thin fibrillin-1 fibers were formed mainly in COL-EL ${ }_{\text {sol }}$, to a lesser extent in COL-EL ${ }_{\text {fiber, }}$, and scarcely in COL (Fig. 6D-F). To some extent, these thin fibers showed colocalization with rat elastin (Fig. 6C, F). Fibrillin-1 staining was found earlier in time than newly synthesized elastin (results not shown) and was more abundant than rat elastin staining (Fig. 6C, F).

\section{DISCUSSION}

In biomaterials, some principal difficulties are observed, including limited vascularization and poor elastogenesis. ${ }^{2,35}$
With regard to the application of elastin as a biomaterial, another difficulty arises because elastin tends to calcify. ${ }^{13,36}$

To induce vascularization and tissue formation, an initial tissue reaction seems to be necessary. COL scaffolds show less reaction than COL-EL $\mathrm{E}_{\mathrm{fiber}}$ or $\mathrm{COL}-\mathrm{EL}_{\mathrm{sol}}$, and little tissue formation was observed after 3 weeks. Tissue reaction is also dependent on the animal model used. In a previous study, we showed that (young and adult) SpragueDawley rats showed more tissue reaction to subcutaneously implanted scaffolds than (adult) Wistar rats. ${ }^{13}$ As a consequence, more vascularization and collagen production was observed in the Sprague-Dawley rats. ${ }^{13,37}$ In this study, COL-EL ${ }_{\text {sol }}$ gave more tissue reaction than COL$\mathrm{EL}_{\text {fiber }}$, and vascularization and tissue formation was even

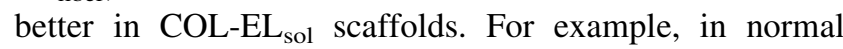
wound healing of the skin, chemotactic signals recruit inflammatory cells to the wound site, initiating the process of reepithelialization and connective tissue contraction and stimulating the angiogenic response. It is important that this tissue reaction, including the presence of neutrophiles, does 
not persist over time, because it is an indication of a grossly infected wound. ${ }^{38}$ In COL-EL sol , neutrophiles were found only sporadically at day 7 . Soluble elastin seems to be able to trigger a cascade for angiogenesis and tissue regeneration. Robinet et al. $^{39}$ recently demonstrated that $\kappa$-elastin (solubilized elastin prepared using potassium hydroxide treatment) triggered angiogenesis by promoting cell migration and tubulogenesis of human vascular endothelial cells through the elastin receptor.

Elastin synthesis is often an obstacle in tissue engineering (e.g., dermal substitutes). ${ }^{40}$ In this study, COL-EL ${ }_{\text {sol }}$ scaffolds were, in particular, able to stimulate the synthesis of elastic fibers in vivo, especially as thread-like structures to which fibrillin-1 staining colocalized. Additional fibrillin-1 staining was found surrounding these structures, suggesting that fibrillin-1 synthesis preceded elastin deposition and that elastin deposition was still in progress. Fibrillin-2 colocalized mainly with newly formed elastic fibers in blood vessels and not with loose thread-like elastic fibers found in COL-EL ${ }_{\text {sol }}$. From mice experiments, it has been suggested that fibrillin-2 directs elastogenesis during embryogenesis, whereas fibrillin-1 is more important in tissue homeostasis. $^{41,42}$ Our experimental setup may resemble tissue regeneration rather than embryogenesis. Furthermore, our results indicate that fibrillin-2 may be more involved in cardiovascular aspects, whereas fibrillin-1 may be more significant in skin. Another study in which skin biopsies were taken from healthy volunteers suggests a similar phenomenon; fibrillin-1 was the major contributor to dermal elastic fiber formation during acute wound repair, whereas fibrillin-2 was expressed only in wounds of the aged, and expression was confined to areas proximal to dermal blood vessels. ${ }^{43}$ Raghunath et al. also found fibrillin-1 preceding elastin deposition in new skin developing from keratinocyte autografts. ${ }^{44}$ Fibrillin-1 may be the template for elastic fiber synthesis in thread-like (skin-like) elastic fibers, whereas fibrillin-2 may be the template for elastogenesis in blood vessels. However, time-resolved expression patterns of fibrillin- 1 and -2 would be necessary to confirm this. Solubilized elastin may be a means to enhance elastic fiber synthesis. It has been suggested that elastin peptides stimulate elastin synthesis through the receptor. ${ }^{6}$ In a porcine skin excision model, improved extracellular matrix remodeling (including elastin regeneration) was found with a collagen-solubilized elastin dermal substitute. ${ }^{45}$ In a clinical study, such a matrix was used in 10 patients as a dermal substitute in severe burn injuries of the hand; full range of hand motion was regained after 3 months. ${ }^{46}$ For a sustained effect of angiogenesis and tissue formation in vivo, a depot of solubilized elastin is recommended. EDC/NHScrosslinked COL-EL sol $_{\text {scaffolds contained solubilized }}$ elastin spheres that could still be detected 21 days after implantation and may thus accomplish their biological effect over a longer period of time.

Calcification is an undesirable phenomenon in soft biomaterial application. Young Sprague-Dawley rats have proven to be a sensitive model for studying calcification. ${ }^{13}$ With COL-EL $L_{\text {sol }}$, we could not detect any calcification in the time frame analyzed, whereas COL-EL $\mathrm{C}_{\text {fiber }}$ showed calcification starting at insoluble elastin fibers. This effect was not due to the presence of fewer macrophages and giant cells in COL-EL sol $_{\text {(and therefore a diminished }}$ release of extracellular enzymes involved in elastin degradation). Negative charges from C-terminal carboxylic groups may be involved in preventing positively charged calcium ions from precipitating, but other mechanisms cannot be excluded based on this study alone. Others have observed calcification of solubilized elastin preparations.

In a similar rat model, Singla and Lee found calcification with collagen- $\alpha$-elastin films stabilized using glutaraldehyde fixation, ${ }^{36}$ but this treatment increases calcification of biomaterials. $^{47}$ In a cranial lesion in adult rats, a polypentapeptide based on elastin with an amino acid sequence of (Val-Pro-Gly-Val-Gly) $)_{n}$ was also able to initiate calcification in vivo, ${ }^{48}$ but it only calcified in a rabbit tibial nonunion model with $n>200$. $^{49}$

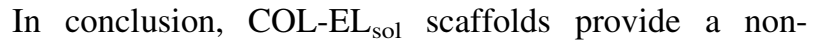
calcifying biomaterial that stimulates angiogenesis and extracellular matrix formation (collagens and elastic fibers) and may be useful in soft tissue engineering.

\section{ACKNOWLEDGMENTS}

This study was financially supported by the Ministry of Economic Affairs (Grant IIE98012), the Dutch Program for Tissue Engineering (Grants DPTE5941 and DPTE6735), and the Canadian Institutes of Health Research (Grant MOP68836). Paul Jap is greatly appreciated for histological evaluations and Jos Dederen for Neurolucida assistance.

\section{REFERENCES}

1. Compton, C.C. Current concepts in pediatric burn care: the biology of cultured epithelial autografts: an eight-year study in pediatric burn patients. Eur. J. Pediatr. Surg. 2, 216, 1992.

2. Kadoya, K., Amano, S., Inomata, S., Tsunenaga, M., Matsuzaki, K., Oshima, H., Tanabe, M., Kumagai, N., and Nishiyama, T. Evaluation of autologous cultured epithelium as replacement skin after tattoo excision: correlation between skin texture and histological features. Br. J. Dermatol. 149, 377, 2003.

3. Berthod, F., Germain, L., Li, H., Xu, W., Damour, O., and Auger, F.A. Collagen fibril network and elastic system remodeling in a reconstructed skin transplanted on nude mice. Matrix Biol. 20, 463, 2001.

4. Senior, R.M., Griffin, G.L., and Mecham, R.P. Chemotactic activity of elastin-derived peptides. J. Clin. Invest. 66, 859, 1980.

5. Kamoun, A., Landeau, J.M., Godeau, G., Wallach, J., Duchesnay, A., Pellat, B., and Hornebeck, W. Growth stimulation 
of human skin fibroblasts by elastin-derived peptides. Cell Adhes. Commun. 3, 273, 1995.

6. Fülöp Jr, T., Jacob, M.P., Khalil, J., Wallach, J., and Robert, L. Biological effects of elastin peptides. Pathol. Biol. (Paris) 46, 497, 1998.

7. Hinek, A., Wang, Y., Liu, K., Mitts, T.F., and Jimenez, F. Proteolytic digest derived from bovine Ligamentum Nuchae stimulates deposition of new elastin-enriched matrix in cultures and transplants of human dermal fibroblasts. J. Dermatol. Sci. 39, 155, 2005.

8. Karnik, S.K., Brooke, B.S., Bayes-Genis, A., Sorensen, L., Wythe, J.D., Schwartz, R.S., Keating, M.T., and Li, D.Y. A critical role for elastin signaling in vascular morphogenesis and disease. Development 130, 411, 2003.

9. Mochizuki, S., Brassart, B., and Hinek, A. Signaling pathways transduced through the elastin receptor facilitate proliferation of arterial smooth muscle cells. J. Biol. Chem. 277, 44854, 2002.

10. Robert, L. Interaction between cells and elastin, the elastinreceptor. Connect. Tissue Res. 40, 75, 1999.

11. Varga, Z., Jacob, M.P., Robert, L., and Fulop, T., Jr. Identification and signal transduction mechanism of elastin peptide receptor in human leukocytes. FEBS Lett. 258, 5, 1989.

12. Rodgers, U.R. and Weiss, A.S. Integrin alpha(v)beta(3) binds a unique non-RGD site near the C-terminus of human tropoelastin. Biochimie 86, 173, 2004.

13. Daamen, W.F., Nillesen, S.T., Hafmans, T., Veerkamp, J.H., Van Luyn, M.J., and Van Kuppevelt, T.H. Tissue response of defined collagen-elastin scaffolds in young and adult rats with special attention to calcification. Biomaterials 26, 81, 2005.

14. Daamen, W.F., Van Moerkerk, H.Th.B., Hafmans, T., Buttafoco, L., Poot, A.A., Veerkamp, J.H., and Van Kuppevelt, T.H. Preparation and evaluation of molecularly-defined collagenelastin-glycosaminoglycan scaffolds for tissue engineering. Biomaterials 24, 4001, 2003.

15. Basalyga, D.M., Simionescu, D.T., Xiong, W., Baxter, B.T., Starcher, B.C., and Vyavahare, N.R. Elastin degradation and calcification in an abdominal aorta injury model: role of matrix metalloproteinases. Circulation 110, 3480, 2004.

16. Abolhoda, A., Yu, S., Oyarzun, J.R., McCormick, J.R., Bogden, J.D., and Gabbay, S. Calcification of bovine pericardium: glutaraldehyde versus No-React biomodification. Ann. Thorac. Surg. 62, 169, 1996.

17. Lee, J.S., Basalyga, D.M., Simionescu, A., Isenburg, J.C., Simionescu, D.T., and Vyavahare, N.R. Elastin calcification in the rat subdermal model is accompanied by up-regulation of degradative and osteogenic cellular responses. Am. J. Pathol. 168, 490, 2006.

18. Hinds, M.T., Courtman, D.W., Goodell, T., Kwong, M., Brant-Zawadzki, H., Burke, A., Fox, B.A., and Gregory, K.W. Biocompatibility of a xenogenic elastin-based biomaterial in a murine implantation model: The role of aluminum chloride pretreatment. J. Biomed. Mater. Res. 69A, 55, 2004.

19. Bailey, M.T., Pillarisetti, S., Xiao, H., and Vyavahare, N.R. Role of elastin in pathologic calcification of xenograft heart valves. J. Biomed. Mater. Res. 66A, 93, 2003.

20. Rossi, M.A. and Santos, C.S. Sepsis-related microvascular myocardial damage with giant cell inflammation and calcification. Virchows Arch. 443, 87, 2003.
21. Kim, Y.H., Han, D.K., Park, K.D., and Kim, S.H. Enhanced blood compatibility of polymers grafted by sulfonated PEO via a negative cilia concept. Biomaterials 24, 2213, 2003.

22. Lin, G., Tiedemann, K., Vollbrandt, T., Peters, H., Batge, B., Brinckmann, J., and Reinhardt, D.P. Homo- and heterotypic fibrillin-1 and -2 interactions constitute the basis for the assembly of microfibrils. J. Biol. Chem. 277, 50795, 2002.

23. Tiedemann, K., Batge, B., Muller, P.K., and Reinhardt, D.P. Interactions of fibrillin-1 with heparin/heparan sulfate, implications for microfibrillar assembly. J. Biol. Chem. 276, 36035, 2001.

24. Pieper, J.S., Oosterhof, A., Dijkstra, P.J., Veerkamp, J.H., and Van Kuppevelt, T.H. Preparation and characterization of porous crosslinked collagenous matrices containing bioavailable chondroitin sulphate. Biomaterials 20, 847, 1999.

25. Daamen, W.F., Hafmans, T., Veerkamp, J.H., and Van Kuppevelt, T.H. Isolation of intact elastin fibers devoid of microfibrils. Tissue Eng. 11, 1168, 2005.

26. Partridge, S.M., Davis, H.F., and Adair, G.S. The chemistry of connective tissues. 2 - Soluble proteins derived from partial hydrolysis of elastin. Biochem. J. 61, 11, 1955.

27. Lowry, O.H., Rosebrough, N.J., Farr, A.L., and Randall, R.J. Protein measurement with the Folin- Phenol reagents. J. Biol. Chem. 193, 265, 1951.

28. Laemmli, U.K. Cleavage of structural proteins during the assembly of the head of bacteriophage T4. Nature 227, 680, 1970.

29. Porath, J. and Flodin, P. Gel filtration: a method for desalting and group separation. Nature 183, 1657, 1959.

30. Görg, A. Two-dimensional electrophoresis. Nature 349, 545, 1991.

31. Olde Damink LH, Dijkstra, P.J., Van Luyn, M.J., Van Wachem, P.B., Nieuwenhuis, P., and Feijen, J. Cross-linking of dermal sheep collagen using a water-soluble carbodiimide. Biomaterials 17, 765, 1996.

32. Daamen, W.F., Hafmans, T., Veerkamp, J.H., and Van Kuppevelt, T.H. Comparison of five procedures for the purification of insoluble elastin. Biomaterials 22, 1997, 2001.

33. Pieper, J.S., Hafmans, T., Veerkamp, J.H., and Van Kuppevelt, T.H. Development of tailor-made collagen-glycosaminoglycan matrices: EDC/NHS crosslinking, and ultrastructural aspects. Biomaterials 21, 581, 2000.

34. Bancroft, J.D. and Stevens, A. Theory and Practice of Histological Techniques. Edinburgh, UK: Churchill Livingstone, 1990.

35. Mooney, D.J. and Mikos, A.G. Growing new organs. Sci. Am. 280, 60, 1999.

36. Singla, A. and Lee, C.H. Effect of elastin on the calcification rate of collagen-elastin matrix systems. J. Biomed. Mater. Res. 60, 368, 2002.

37. Nillesen, S.T., Geutjes, P.J., Wismans, R., Schalkwijk, J., Daamen, W.F., and Van Kuppevelt, T.H. Increased angiogenesis and blood vessel maturation in acellular collagen-heparin scaffolds containing both FGF2 and VEGF. Biomaterials 28, 1123, 2007.

38. Martin, P. Wound healing-aiming for perfect skin regeneration. Science 276, 75, 1997.

39. Robinet, A., Fahem, A., Cauchard, J.H., Huet, E., Vincent, L., Lorimier, S., Antonicelli, F., Soria, C., Crepin, M., Hornebeck, W., and Bellon, G. Elastin-derived peptides enhance 
angiogenesis by promoting endothelial cell migration and tubulogenesis through upregulation of MT1-MMP. J. Cell Sci. 118, 343, 2005.

40. Truong, A.T., Kowal-Vern, A., Latenser, B.A., Wiley, D.E., and Walter, R.J. Comparison of dermal substitutes in wound healing utilizing a nude mouse model. J. Burns Wounds 4, e4, 2005.

41. Ramirez, F. and Pereira, L. The fibrillins. Int. J. Biochem. Cell Biol. 31, 255, 1999.

42. Pereira, L., Andrikopoulos, K., Tian, J., Lee, S.Y., Keene, D.R., Ono, R., Reinhardt, D.P., Sakai, L.Y., Biery, N.J., Bunton, T., Dietz, H.C., and Ramirez, F. Targetting of the gene encoding fibrillin-1 recapitulates the vascular aspect of Marfan syndrome. Nat. Genet. 17, 218, 1997.

43. Ashcroft, G.S., Kielty, C.M., Horan, M.A., and Ferguson, M.W. Age-related changes in the temporal and spatial distributions of fibrillin and elastin mRNAs and proteins in acute cutaneous wounds of healthy humans. J. Pathol. 183, 80, 1997.

44. Raghunath, M., Bachi, T., Meuli, M., Altermatt, S., Gobet, R., Bruckner-Tuderman, L., and Steinmann, B. Fibrillin and elastin expression in skin regenerating from cultured keratinocyte autografts: morphogenesis of microfibrils begins at the dermo-epidermal junction and precedes elastic fiber formation. J. Invest. Dermatol. 106, 1090, 1996.

45. Lamme, E.N., De Vries, H.J., Van Veen, H., Gabbiani, G., Westerhof, W., and Middelkoop, E. Extracellular matrix characterization during healing of full-thickness wounds treated with a collagen/elastin dermal substitute shows improved skin regeneration in pigs. J. Histochem. Cytochem. 44, 1311, 1996.

46. Haslik, W., Kamolz, L.P., Nathschlager, G., Andel, H., Meissl, G., and Frey, M. First experiences with the collagenelastin matrix Matriderm as a dermal substitute in severe burn injuries of the hand. Burns 33, 364, 2007.

47. Nimni, M.E., Myers, D., Ertl, D., and Han, B. Factors which affect the calcification of tissue-derived bioprostheses. J. Biomed. Mater. Res. 35, 531, 1997.

48. Hollinger, J.O., Schmitz, J.P., Yaskovich, R., Long, M.M., Prasad, K.U., and Urry, D.W. A synthetic polypentapeptide of elastin for initiating calcification. Calcif. Tissue Int. 42, 231, 1988.

49. Wood, S.A., Lemons, J.E., Prasad, K.U., and Urry, D.W. In vitro calcification and in vivo biocompatibility of the cross-linked polypentapeptide of elastin. J. Biomed. Mater. Res. 20,315, 1986.

Address reprint requests to: Willeke F. Daamen, Ph.D.

Dept. of Biochemistry 280

Nijmegen Centre for Molecular Life Sciences Radboud University Nijmegen Medical Centre

P.O. Box 9101

$6500 \mathrm{HB}$ Nijmegen

The Netherlands

E-mail: w.daamen@ncmls.ru.nl 


\section{This article has been cited by:}

1. Chloe N. Grover, Ruth E. Cameron, Serena M. Best. 2012. Investigating the morphological, mechanical and degradation properties of scaffolds comprising collagen, gelatin and elastin for use in soft tissue engineering. Journal of the Mechanical Behavior of Biomedical Materials 10, 62-74. [CrossRef]

2. Jelena Rnjak-Kovacina, Steven G. Wise, Zhe Li, Peter K.M. Maitz, Cara J. Young, Yiwei Wang, Anthony S. Weiss. 2012. Electrospun synthetic human elastin:collagen composite scaffolds for dermal tissue engineering. Acta Biomaterialia . [CrossRef]

3. Andreia Vasconcelos, Andreia C. Gomes, Artur Cavaco-Paulo. 2012. Novel silk fibroin/elastin wound dressings. Acta Biomaterialia . [CrossRef]

4. Willeke Daamen, Kaeuis Faraj, Martin Koens, Gerwen Lammers, Katrien Brouwer, Peter Uijtdewilligen, Suzan Nillesen, Luc Roelofs, Jody Nuininga, Paul Geutjes, Wouter Feitz, Toin van KuppeveltExtracellular Matrix-Based Scaffolds from Scratch 385-398. [CrossRef]

5. Jelena Rnjak-Kovacina, Steven G. Wise, Zhe Li, Peter K.M. Maitz, Cara J. Young, Yiwei Wang, Anthony S. Weiss. 2011. Tailoring the porosity and pore size of electrospun synthetic human elastin scaffolds for dermal tissue engineering. Biomaterials . [CrossRef]

6. Jelena Rnjak, Steven G. Wise, Suzanne M. Mithieux , Anthony S. Weiss . 2011. Severe Burn Injuries and the Role of Elastin in the Design of Dermal Substitutes. Tissue Engineering Part B: Reviews 17:2, 81-91. [Abstract] [Full Text HTML] [Full Text PDF] [Full Text PDF with Links]

7. S.T.M. Nillesen, G. Lammers, R.G. Wismans, M.M. Ulrich, E. Middelkoop, P.H. Spauwen, K.A. Faraj, J. Schalkwijk, W.F. Daamen, T.H. van Kuppevelt. 2011. Design and in vivo evaluation of a molecularly defined acellular skin construct: Reduction of early contraction and increase in early blood vessel formation. Acta Biomaterialia 7:3, 1063-1071. [CrossRef]

8. Kai-Jye Lou. 2011. Fusion factor. Science-Business eXchange 4:4. . [CrossRef]

9. P. Koria, H. Yagi, Y. Kitagawa, Z. Megeed, Y. Nahmias, R. Sheridan, M. L. Yarmush. 2011. Self-assembling elastin-like peptides growth factor chimeric nanoparticles for the treatment of chronic wounds. Proceedings of the National Academy of Sciences 108:3, 1034-1039. [CrossRef]

10. J. Rnjak-Kovacina, W.F. Daamen, M. Pierna, J.C. Rodríguez-Cabello, A.S. WeissElastin Biopolymers 329-346. [CrossRef]

11. S. Bierbaum, D. ScharnweberArtificial Extracellular Matrices to Functionalize Biomaterial Surfaces 127-153. [CrossRef]

12. Wiltrud R. Meyer, Rudolf Schopf, Claudius U. Meyer, Henrik Menke. 2010. Laminar Implantation of a Collagen-Elastin Matrix Improves Infraorbital Contour in Aesthetic Facial Surgery. Plastic and Reconstructive Surgery 126:5, 1756-1760. [CrossRef]

13. Divya Pankajakshan, Devendra K. Agrawal. 2010. Scaffolds in tissue engineering of blood vessels. Canadian Journal of Physiology and Pharmacology 88:9, 855-873. [CrossRef]

14. Xiaolan Ba, Miriam Rafailovich, Yizhi Meng, Nadine Pernodet, Sue Wirick, Helga Füredi-Milhofer, Yi-Xian Qin, Elaine DiMasi. 2010. Complementary effects of multi-protein components on biomineralization in vitro. Journal of Structural Biology 170:1, 83-92. [CrossRef]

15. Preface $x v$-xix. [Citation] [Full Text PDF] [Full Text PDF with Links]

16. P. MARTENS, A. NILASAROYA, L. A. POOLE-WARRENMaterials facilitating protein drug delivery and vascularisation 179-203. [CrossRef]

17. G. Lammers, G.S. Tjabringa, J. Schalkwijk, W.F. Daamen, T.H. van Kuppevelt. 2009. A molecularly defined array based on native fibrillar collagen for the assessment of skin tissue engineering biomaterials. Biomaterials 30:31, 6213-6220. [CrossRef]

18. Suzanne M. Mithieux, Yidong Tu, Emine Korkmaz, Filip Braet, Anthony S. Weiss. 2009. In situ polymerization of tropoelastin in the absence of chemical cross-linking. Biomaterials 30:4, 431-435. [CrossRef]

19. Letizia Mattii, Barbara Battolla, Delfo D'Alessandro, Luisa Trombi, Simone Pacini, Maria Grazia Cascone, Luigi Lazzeri, Nunzia Bernardini, Amelio Dolfi, Sara Galimberti, Mario Petrini. 2008. Gelatin/PLLA Sponge-Like Scaffolds Allow Proliferation and Osteogenic Differentiation of Human Mesenchymal Stromal Cells. Macromolecular Bioscience 8:9, 819-826. [CrossRef]

20. Peter C. Johnson, Antonios G. Mikos Advances in Tissue Engineering, Volume 1: Angiogenesis . [Citation] [Full Text HTML] [Full Text PDF] [Full Text PDF with Links] 